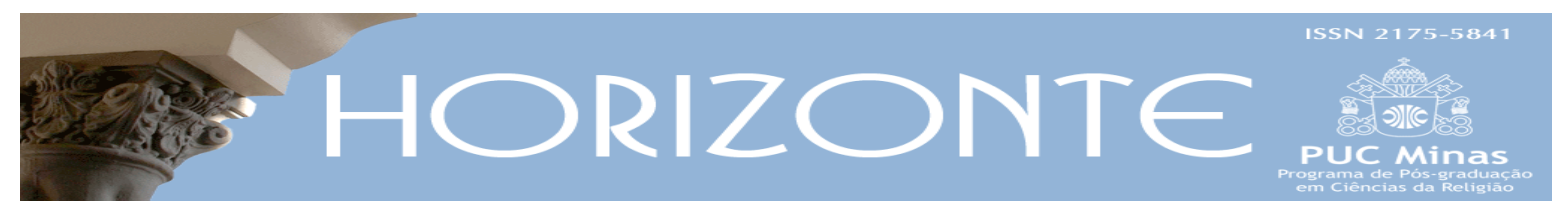

Dossiê: Teorias de linguagem e Estudos de Religião - Artigo Original ๑을

\title{
A semiótica greimasiana no quadro epistemológico das teorias da linguagem e dos estudos da religião
}

\author{
Greimasian's semiotics in the epistemological framework of Language \\ theories and religion studies
}

Sueli Maria Ramos da Silva*

\begin{abstract}
Resumo
Este artigo tem por objetivo proceder à relação entre as teorias da linguagem e o estudo das religiões, notadamente por meio da apresentação do quadro epistemológico da semiótica greimasiana de linha francesa. O artigo, de natureza teórica, ao observar as recorrências dos mecanismos de construção do sentido dos textos, presentes nos enunciados de interpretação religiosa, efetivados pela semiótica, procura realizar um breve histórico desses estudos, traçando algumas considerações acerca de como se processa o projeto da semiótica no que concerne ao tratamento de enunciados das linguagens da religião. Do mesmo modo que a área que trata das Linguagens da Religião, a semiótica greimasiana da qual trabalhamos, difere-se de propostas centradas nos aspectos de comunicação religiosa e nos aspectos de relações midiáticas, tomando por base os aspectos mais elementares da relação entre religião e linguagem. Ao tomarmos a religião como prática social, presente no espaço tensivo das práticas, esperamos contribuir com a apresentação de uma epistemologia diferenciada no que concerne ao tratamento das linguagens da religião.
\end{abstract}

Palavras-chaves: teorias da linguagem e da religião; semiótica greimasiana; epistemologia.

\begin{abstract}
The aim of this article is to relate theories of language to the study of religions, especially through the presentation of the epistemological framework of the Greimasian's semiotics of the French line. The theoretical article, when observing the recurrences of the mechanisms of construction of the sense of the texts, present in the statements of religious interpretation, effected by the semiotics, tries to draw a brief history of these studies, drawing some considerations about how the project of the semiotics regarding the treatment of statements of the languages of religion. Just as the area dealing with the languages of religion differs from proposals centered on the aspects of religious communication and aspects of media relations, based on the most elementary aspects of religion and language, so does the Greimasian's semiotics of which we work. When we take religion as a social practice, present in the tensional space of practices, we hope to contribute with the presentation of a differentiated epistemology regarding the treatment of the languages of religion.
\end{abstract}

Keywords: theories of language and religion; greimasian's semiotics; epistemology.

Artigo submetido em 31 de julho de 2018 e aprovado em 02 de outubro de 2018.

* Doutora em Semiótica e Linguística geral - FFLCH-USP (2012). Professora adjunta da Universidade Federal do Mato Grosso do Sul. País de origem: Brasil. E-mail: profa.dra.sueliramos@gmail.com 


\title{
Introdução
}

\begin{abstract}
Nenhum fato, coisa ou gesto, entretanto, é encontrado já com as marcas do sagrado. O sagrado não é uma eficácia inerente às coisas. Ao contrário, coisas e gestos se tornam religiosos quando os homens os batizam como tais. A religião nasce com o poder que os homens têm de dar nomes às coisas, fazendo uma discriminação entre as coisas de importância secundária e as coisas nas quais seu destino, sua vida e sua morte se dependuram. Esta é a razão por que, fazendo uma abstração dos sentimentos e experiências pessoais que acompanham o encontro com o sagrado, a religião se nos apresenta como um tipo de fala, um discurso, uma rede de símbolos. Com esses símbolos os homens discriminam objetos, tempos e espaços, construindo com seu auxílio, uma abóbada sagrada com que recobrem seu mundo. (ALVES, 2005, p. 25).
\end{abstract}

Antes de procedermos às relações entre teorias da linguagem, notadamente a semiótica greimasiana de linha francesa, e o estudo das religiões, procuraremos, motivados pelos estudos de Nogueira (2016), situar nosso posicionamento epistemológico. Cabe ressaltar a epistemologia enquanto "análise dos axiomas, das hipóteses e dos procedimentos, e mesmo dos resultados que especificam uma dada ciência" (GREIMAS; COURTÉS, 2008, p. 173). Nogueira (2016), ao ressaltar a complexa relação entre religião e linguagem, apresenta todo o seu alicerce teórico fundamentado nos estudos da semiótica da cultura de Iuri Lotman. Entretanto, como o autor procura destacar, a perspectiva destacada não é vista como excludente, nem tampouco como a única possível. Assim sendo, julgamos de extrema importância correlacionar os estudos acerca da teoria semiótica greimasiana de linha francesa, alicerçada pelos novos desenvolvimentos que se têm feito por meio de seus novos desdobramentos, a saber, a semiótica tensiva e a semiótica das práxis enunciativas desenvolvida por Fontanille (2008). A fundamentação teórica utilizada, ao compreender a análise semiótica como princípio de método de exegese de textos religiosos, será amparada pelos desenvolvimentos de Chabrol (1980), Panier (1986, 1989, 2008) e Silva (2013), na medida em que procuraremos traçar um breve histórico desses estudos, tecendo algumas considerações acerca de como se processa o projeto da semiótica no que concerne ao tratamento de enunciados das linguagens da religião.

Assim sendo, desenvolvemos este artigo em duas partes. Na primeira parte, esboçamos um breve histórico do desenvolvimento dos estudos linguísticos, tendo 
por base a linguística e a cientificidade nos estudos da língua, destacando como a primeira fase dos estudos linguísticos foram alicerçados por razões religiosas.

Após o estabelecimento das diretrizes dos estudos linguísticos, originariamente desenvolvidos com a finalidade de se descrever o funcionamento da linguagem humana, passaremos, na seção seguinte, à exposição da teoria semiótica de base saussuriana, a semiótica greimasiana de linha francesa, destacando-se sua primazia acerca da linguagem religiosa.

\section{Linguística e a cientificidade nos estudos da linguagem}

A linguagem sempre exerceu fascínio sobre o homem. Nesta seção nos pautaremos pela apresentação das características do estudo da linguagem, dotadas por um viés científico, tal como a linguística estabeleceu como objeto de estudo. Assim sendo, cabe discutirmos algumas das premissas que a instituíram como objeto de estudo acadêmico, assim como traçar o histórico do desenvolvimento da linguística nas ciências da linguagem.

De início, podemos atribuir o fascínio do homem pela linguagem aos mitos, ritos, lendas, cantos, rituais, trabalhos eruditos, etc. A linguagem era associada ao poder mágico criador, capaz de dar existência à coisas e realidades. Assim, temos a primeira fase dos estudos da linguagem que a procuravam associar aos mitos criadores. Por meio deles se procurava explicar a origem da linguagem e a diversidade das línguas.

Tomemos, por exemplo, em conformidade com Fiorin (2013), a narrativa de Gênesis na qual se dá a passagem do caos à ordem por meio de um ato linguageiro que dá sentido ao mundo. É na e pela linguagem que se ordena o mundo.

1 No princípio, Deus criou o céu e a terra. 2 A terra estava sem forma e vazia; as trevas cobriam o abismo e o Espírito Santo de Deus pairava sobre as águas. 3 Deus disse: "Faça-se a luz". E a luz foi feita. 4 Deus viu que a luz era boa, e separou a luz e as trevas. 5 Deus chamou a luz dia, e às trevas noite. Sobreveio a tarde e depois a manhã: foi o primeiro dia. (Gênesis I, 1-5). 
O mito é capaz de demonstrar por meio da linguagem as categorias criadoras do sentido. Segundo Fiorin (2013, p. 34), a linguagem adâmica também é apresentada na narrativa de Gênesis como responsável pela apreensão e categorização da realidade. $\mathrm{O}$ ato de denominação realizado é uma faculdade divina atribuída em forma de competência a Adão. Ele, ao denominar cada uma das realidades preexistentes, torna-se capaz de apreender o mundo.

18. O Senhor Deus disse: "Não é bom que o homem esteja só. Vou dar-lhe uma auxiliar que lhe seja adequada". 19. Tendo, pois, o Senhor Deus formado da terra todos os animais dos campos, e todas as aves do céu, levou-os ao homem, para ver como ele os havia de chamar; e todo o nome que o homem pôs aos animais vivos, esse é seu verdadeiro nome. 20. $\mathrm{O}$ homem pôs nomes a todos os animais, a todas as aves do céu e a todos os animais do campo [...]. (Gênesis II, 18-20).

A preocupação com os estudos da linguagem é tão remota quanto as próprias civilizações. Também por razões religiosas se desenvolveram os primeiros estudos a respeito da linguagem. Por volta do século IV A.C, tiveram desenvolvimento os estudos da linguagem pelos hindus, cujo objetivo principal era de que os textos sagrados dos Vedas não apresentassem modificações à medida que fossem pronunciados.

Segundo Saussure (1975, p. 7), antes de se conhecer seu verdadeiro e único objeto, a ciência, que se constituiu em torno dos fatos da língua, apresentou três fases sucessivas (gramática, filologia, filologia comparativa ou gramática comparada), cujas características estabelecemos a seguir.

A primeira fase, denominada fase gramatical, apresentou as primeiras especulações gregas sobre a origem, história e estrutura da linguagem. Essas primeiras especulações eram de origem filosófica por meio da relação entre pensamento e palavra, as coisas e seus nomes. As discussões pairavam em torno do seguinte questionamento: "há uma relação natural entre a palavra e a coisa ou procede-se arbitrariamente segundo o uso" (BORBA, 1979, p. 13). A primeira dessas discussões aparece no Crátilo de Platão. Discutia-se acerca da convencionalidade dos signos linguísticos. Seriam os sentidos das palavras presos às suas formas gramaticais? 
A decadência literária vivida na Alexandria fez com que a preocupação dos estudos gramaticais gregos recaísse sobre a interpretação e reconstrução da antiga literatura. Assim nasceu a gramática (grámmata, lat. Literae), cujo interesse residia nas obras escritas. Mais tarde, os estudos concentrados em torno da língua restringiram esses estudos às questões de língua e dos fundamentos da linguagem. Os estudos gramaticais apresentavam, assim, um caráter normativo, ligado à crítica dos textos. Por meio dos estudos gramaticais eram realizadas reflexões acerca das declinações, conjugações, vozes, tempos verbais, partes do discurso, além das categorias gramaticais (nome, verbo, particípio, artigo, pronome, proposição, advérbio e conjugação). Dentre os autores que mereceram destaque nesse período temos Dionísio da Trácia. Dentre as características de sua gramática podemos destacar: “1. Leitura e pronúncia correta. 2. Explicação dos textos pelos tropos que neles surgem. 3. Explicação de palavras e coisas. 4. Etimologia. 5. Paradigma de flexão ou analogia. 6. Crítica” (BORBA, 1979, p. 15). A esses estudos se seguiram os estudos de morfologia e de sintaxe.

Essas especulações gramaticais apresentavam algumas restrições. Uma delas era sua preocupação exclusivamente filosófica e lógica. Não era um estudo que priorizava de modo direto a observação dos fatos da língua, nem tampouco a comparação com outras línguas, sendo restritos ao grego como língua nacional. Assim sendo, esses estudos tinham como característica prioritária o estudo da língua vernácula, o grego, como um fim prático para preservação de textos antigos, dos quais podemos destacar a Ilíada e a Odisséia. Isso fez com que muitas de suas especulações resultassem em conclusões falsas e etimologias fantasiosas. Outras dessas restrições são a sua considerável abstração e normatividade. A seguir, se desenvolveu o modelo gramatical em Roma, devidamente construído sobre o modelo grego. Os conhecimentos gregos foram aplicados ao modelo latino. Desse período merece destaque a gramática de Varrão (116 a 27 A.C) - De língua latina. Os gramáticos romanos apresentavam a mesma limitação dos gregos: dependência da filosofia e atenção à língua nacional. Ainda nesse período, merecem destaque os gramáticos hindus, que tiveram papel importante na história da língua por meio da criação de uma gramática comparativa das línguas indo-europeias determinada 
pelo estudo do sânscrito. Temos, ainda, os estudos gramaticais na Idade Média, com destaque à romanização latina. Nesse período, devido a própria romanização, a escrita do latim clássico era concebida como a forma logicamente formal da linguagem humana. Nesse período merece destaque a Grammaire génerale et raisonnée de Port Royal (1660). Assim sendo, podemos tecer, de acordo com Saussure (1975, p. 7) as características centrais dos estudos gramaticais dos quais podemos destacar seu caráter acientífico, prescritivo e normativo. Ao afastar-se da observação e de qualquer visão científica e desinteressada da língua preocupa-se com a formulação de regras e de predições.

A segunda fase dos estudos da linguagem é denominada de fase dos estudos filológicos. O termo filologia advém da antiguidade e representa o gosto pela convenção elegante, erudita e artística. O objeto dos estudos da língua são os textos, mediante os quais se devem tecer interpretações e comentários, dando sua devida atenção à língua escrita.

A terceira fase dos estudos da linguagem, o comparativismo, corresponde à entrada no período científico da linguística. Passamos a denominar, assim, de período pré-científico aquele anterior à gramática comparativa e de científico o período posterior ao advento da gramática comparada. Esse período compreende o advento da comparação das línguas entre si, a fim de assinalar afinidades e reagrupar famílias de línguas. Merece destaque a obra do comparativista Franz Bopp ao elaborar um estudo das relações que unem o sânscrito ao germânico, ao grego e ao latim.

Entretanto, apesar de seu incontestável mérito, essa escola não se constituiu, segundo Saussure (1975, p. 10), como uma verdadeira ciência linguística, de tal forma a jamais ter se preocupado com a determinação de seu objeto de estudo.

Ora, segundo o autor, sem essa operação elementar de determinação de um objeto de estudo, "uma ciência é incapaz de estabelecer um método para si própria" (SAUSSURE, 1975, p. 10). Ainda segundo Saussure (1975, p. 10), um dos primeiros erros que não a constituíram uma ciência linguística é o fato de jamais terem 
questionado a que se levariam as comparações feitas, ou o significado das analogias descobertas. Teria sido exclusivamente comparativa, ao invés de histórica. Afirma Saussure:

Somente em 1870 aproximadamente foi que se indagou quais seriam as condições de vida das línguas. Percebeu-se então que as correspondências que as unem não passam de um dos aspectos do fenômeno linguístico, que a comparação não é senão um meio, um método para reconstruir os fatos. (SAUSSURE, 1975, p. 11).

A Linguística propriamente dita tem sua origem nos estudos das línguas românicas e germânicas. Segundo Saussure (1975, p. 11) "os estudos românicos inaugurados por Diez - sua Gramática das Línguas Românicas data de 1836-1838 - contribuiriam para aproximar a linguística de seu verdadeiro objeto”. O primeiro impulso para o desenvolvimento da linguística propriamente dita se deu por meio da escola dos Neogramáticos. Essa escola teve como premissas a organização histórica dos resultados da comparação, elencando os fatos em ordem natural. "Graças aos neogramáticos, não se viu mais na língua um organismo que se desenvolve por si, mas um produto do espírito coletivo dos grupos linguísticos” (SAUSSURE, 1975, p. 12). A matéria e a tarefa da linguística passa a ser sua relação com as ciências conexas.

A matéria da linguística é constituída inicialmente por todas as manifestações da linguagem humana, que se trate de povos selvagens ou de nações civilizadas, de épocas arcaicas, clássicas ou de decadência, considerando-se em cada período não só a linguagem correta e a "bela linguagem", mas todas as formas de expressão. (SAUSSURE, 1975, p. 13).

Assim sendo, é tarefa da linguística realizar a descrição e história das línguas, estabelecer a dedução de leis gerais, delimitar-se e definir-se a si própria. A linguística apresenta ainda relação com outras ciências. Se a linguística é concebida como a ciência que tem por objeto a linguagem, "tanto a linguagem quanto as línguas podem ser estudadas sob diferentes pontos de vista. Portanto, o campo total da linguística pode ser dividido em diversos subcampos segundo o ponto de vista adotado ou a ênfase dada a um conjunto de fenômenos, ou premissas, ao invés do outro" (LYONS, 2011, p. 25). Os estudos linguísticos podem ser concebidos em conformidade com as seguintes dicotomias: a) linguística geral e 
descritiva; b) sincronia e diacronia; c) linguística teórica e aplicada; d) macrolinguística e microlinguística. A primeira distinção que se deve estabelecer é entre o que poderíamos compreender como uma linguística geral em oposição a uma linguística descritiva, embora elas não sejam completamente estanques, dependendo uma da outra. "A linguística geral fornece os conceitos e categorias em termo dos quais as línguas serão analisadas. A linguística descritiva, por sua vez, fornece dados que confirmam ou refutam as proposições e teorias colocadas pela linguística geral” (LYONS, 2011, p. 25). A segunda oposição concerne à sincronia vs. diacronia dos estudos linguísticos. Por estudos sincrônicos temos a determinação do estado de uma determinada língua conforme o estágio em que ela se encontra no tempo. Por descrição diacrônica compreende-se o registro e desenvolvimento das mudanças históricas em uma sucessividade temporal. No que concerne à terceira dicotomia temos a linguística teórica que "estuda a linguagem e as línguas com vistas a construir uma teoria de suas estruturas e funções, independente de quaisquer aplicações práticas que a investigação da linguagem e das línguas possa ter” (LYONS, 2011, p. 26). Em oposição à linguística teórica temos a linguística aplicada que se ocupa "da aplicação dos conceitos e descobertas da linguística a uma série de tarefas práticas, inclusive do ensino de línguas” (LYONS, 2011, p. 26). A terceira e última dicotomia envolve a macrolinguística de visão ampla dos fatos da linguagem e a visão estreita que se ocupa unicamente dos sistemas linguísticos.

Feitas essas considerações acerca da natureza dos estudos da linguagem e de um breve histórico dessas preocupações, tomemos o caráter científico da linguagem, objeto de nossa discussão.

Define-se normalmente a linguística como ciência da linguagem (estudo científico da linguagem). Entretanto, cabe discutirmos o porquê de se discutir o status científico da disciplina, questão presente em inúmeros manuais de linguística. Lyons (2011), afirma que essa discussão deve ser salientada na própria palavra inglesa "Science" de abrangência menor do que outras traduções tais como "wissenchaft" em alemão, "nauke" em russo e até mesmo "Science” em francês. "A 
linguística, mais do que a maioria das outras disciplinas, sofre das implicações muito específicas das palavras inglesas "Science" e "Scientific" que se referem, antes de mais nada, às ciências naturais e aos meios de investigação que lhes são característicos” (LYONS, 2011, p. 27). Seria ciência meramente uma disciplina acadêmica? A maioria dos linguistas que tomam a afirmação de que se trata de um estudo científico da língua estabelecem a oposição de que existe um modo científico e um modo acientífico de se realizar essa tarefa (LYONS, 2011, p. 27). Tomemos algumas definições que corroboram essa afirmação, assim como o status científico da disciplina. A linguística é empírica e não especulativa ou intuitiva. Ela "opera com dados publicamente verificáveis por meio de observações e experiência” (LYONS, 2011, p. 27). Muito do caráter científico da linguagem advém de sua oposição às premissas da gramática tradicional, de tal forma a se afirmar o status científico de uma por oposição ao caráter acientífico da outra. Assim sendo, caracterizamos os estudos linguísticos por seu empirismo e objetividade. “A linguística é uma ciência humana, de caráter empírico, sem preocupações normativas - o linguista observa, interpreta, classifica, mas não julga nem prescreve usos” (BORBA, 1979, p. 9). Borba (1979, p. 9) afirma que a linguística permaneceu no Brasil como uma disciplina sem aplicação prática imediata, cujo escopo seria o deleite intelectual. Entretanto, seu interesse é determinar o funcionamento e a estrutura da linguagem. Tomemos, a seguir, a conceituação geral estabelecida por Borba:

A linguística é uma ciência que procura determinar, com métodos próprios, a estrutura e a função da linguagem humana. Como a linguagem humana, isto é a capacidade que tem o homem de comunicar-se por meio de sons articulados em si, é uma abstração, a linguística procura a concretização da linguagem, ou seja, as línguas. (BORBA, 1979, p. 36).

Seu objeto de estudo é a linguagem "sistema de elementos sonoros de que os homens se servem para comunicar seus sentimentos, volições e pensamentos (BORBA, 1979, p. 36). Para Saussure, a linguística é parte de uma ciência geral, a semiologia, que tem por tarefa "definir o que faz da língua um sistema especial no conjunto dos fatos semiológicos" (SAUSSURE, 1975, p. 24). Assim, no início do século XX, mediante a divulgação dos trabalhos de Saussure, a investigação sobre a 
linguagem passa a se tornar um estudo científico. "O método científico supõe que a observação dos fatos seja anterior ao aparecimento de uma hipótese e que os fatos observados sejam examinados mediante experimentação e uma teoria adequada". (FIORIN, 2003, p. 13). A distinção entre linguagem, língua e fala situa o objeto da linguística para Saussure. Para Saussure (1975, p. 17), a linguagem é "heteróclita e multifacetada, pois abrange vários domínios, é ao mesmo tempo física, fisiológica e psíquica, pertence ao domínio social e individual, não se deixa classificar em nenhuma categoria dos fatos humanos", podendo ser estudada por outras disciplinas. Saussure estabelece a língua como objeto de estudo linguístico, ela é para Saussure, "a parte essencial da linguagem, exterior ao indivíduo; não pode ser modificada pelo falante e obedece às leis do contrato social estabelecido pelos membros da comunidade”. A fala não é para Saussure objeto da linguagem por ser individual, própria ao falante. Se a linguagem é o objeto de estudo da linguística cabe tecermos algumas definições.

A linguística não se compara ao estudo tradicional da gramática; ao observar a língua em uso o linguista procura descrever e explicar os fatos: os padrões sonoros e lexicais que estão sendo usados, sem avaliar aquele uso em termos de outro padrão: moral, estético ou crítico. (FIORIN, 2003, p. 17).

A Linguística é descritiva, não normativa. "A linguística, portanto, como qualquer ciência, descreve seu objeto como ele é, não especula nem faz afirmações sobre como a língua deveria ser" (FIORIN, 2003, p. 21). Diante dessa postura teórico-metodológica, advém o "caráter científico da Linguística, que se fundamenta em dois princípios: o empirismo e a objetividade" (FIORIN, 2003, p. 21). "A Linguística tem por finalidade elucidar o funcionamento da linguagem humana, descrevendo e explicando a estrutura e o uso das diferentes línguas faladas no mundo. Esse é o seu objeto empírico.” (FIORIN, 2013, p. 42).

\section{A Semiótica Greimasiana e os estudos acerca de religião/religiosidade}

Uma das mudanças fundamentais realizadas pelos estudos linguísticos refere-se ao fato de se poder ter reconhecido "que a linguagem deveria ser descrita como uma estrutura formal" (BENVENISTE, 2005, p. 127). Cabe ressaltar que 
“essa descrição exigia antes de tudo, o estabelecimento de procedimentos e de critérios adequados e que em suma a realidade do objeto não era separável do método próprio para defini-lo” (BENVENISTE, 2005, p. 127).

A semiótica greimasiana, inicialmente denominada como ciência geral na qual se inserem os estudos linguísticos, corresponde, de acordo com Greimas e Courtés (2008, p. 452), "na tipologia de Hjelmslev, à metassemiótica chamada semiologia”. A semiótica insere-se dentro desta perspectiva, ao se apresentar como uma teoria da significação, cuja "sua primeira preocupação será, pois, explicitar sob forma de construção conceitual, as condições da apreensão e da produção do sentido" (GREIMAS; COURTÉS, 2008, p. 455). Situando-nos na tradição saussuriana e hjelmsleviana, "segundo a qual a significação é a criação e/ou a apreensão das diferenças” (GREIMAS; COURTÉS, 2008, p. 455), tomamos a definição do método científico formal como elemento basilar para estabelecer a definição da estrutura elementar da significação, capaz de elucidar o funcionamento discursivo da linguagem humana, tomada neste artigo em um objeto específico, a linguagem religiosa. Concebendo a dimensão discursiva das práticas sociais materializada por meio da noção de texto, inserimo-nos, para tanto, no quadro epistemológico da semiótica greimasiana de linha francesa.

A Semiótica greimasiana pauta-se, na busca de definição de sentido do seu objeto, entendido enquanto texto, concernente a toda e qualquer manifestação linguageira presente nas práticas sociais. Essa busca apresenta-se segundo a forma de um percurso gerativo do sentido, que comporta três níveis de análise: fundamental, narrativo e discursivo. Podemos, segundo Fiorin (2005, p. 20), entender o percurso gerativo do sentido como uma sucessão de patamares, em que cada um dos níveis compõe-se de um componente sintático e de um componente semântico, sendo suscetíveis de receber uma descrição adequada a fim de se demonstrar como se processa o mecanismo de produção do sentido, em um processo que caminha do mais simples ao mais complexo. 


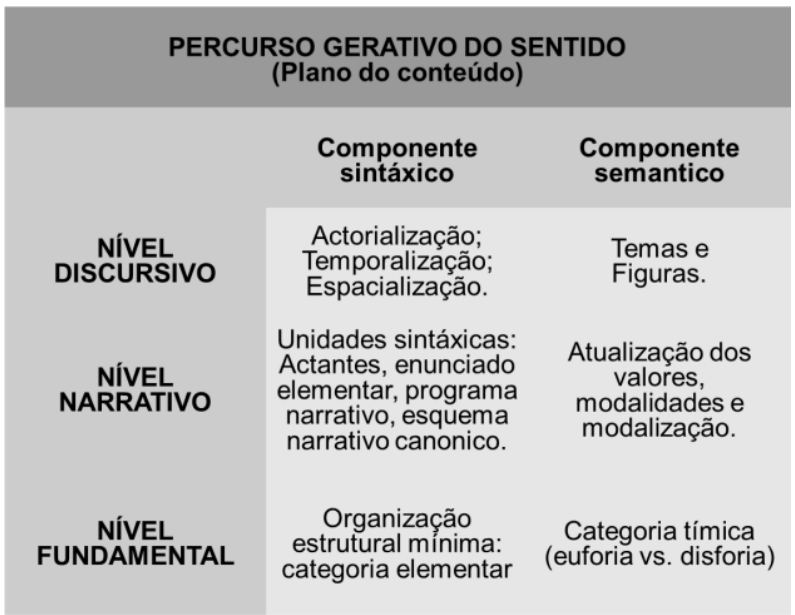

Figura 1. Percurso gerativo do sentido. Baseado em Fiorin (2005, p. 20).

Temos, assim, a organização fundamental mínima do texto, denominada nível fundamental, segundo a qual o texto organiza-se segundo a axiologia euforia vs. disforia, em conformidade a categoria tímica apresentada pelo texto. Os valores do nível fundamental convertem-se em estruturas narrativas. Nesse nível, ocorre o investimento dos objetos valor, segundo o qual o sujeito é investido pela relação transitiva com o objeto-valor. O sintagma elementar do nível narrativo é o programa narrativo. Os percursos narrativos, reconhecíveis como da manipulação, da ação (competência e perfórmance) e da sanção, podem ser compreendidos como organizações hierárquicas de programas narrativos PNs. No nível discursivo temos a assunção dos valores. Esse é considerado o patamar mais superficial do percurso gerativo do sentido, o mais próximo da manifestação textual. "As estruturas narrativas convertem-se em estruturas discursivas quando assumidas pelo sujeito da enunciação. O sujeito da enunciação faz uma série de escolhas, de pessoa, de tempo, de espaço, de figuras, e 'conta' ou passa a narrativa transformando-a em discurso" (BARROS, 2005, p. 53). Segundo Barros (2005, p. 53-54), análise discursiva embora utilize os mesmos elementos da análise narrativa, estabelece como aspectos a serem analisados alguns pontos que haviam sido postos de lado, quais sejam: a) projeções da enunciação no enunciado; b) recursos de persuasão empregados pelo enunciador para manipular o enunciatário; c) cobertura figurativa dos conteúdos narrativos abstratos. A passagem para o nível discursivo 
ocorre mediante a instauração da enunciação, instância responsável pela mediação entre as estruturas narrativas e discursivas (BARROS, 2005, p. 54).

Entretanto, as proposições do modelo padrão alicerçavam-se meramente na dimensão textual dos discursos, de modo a se fazer necessário correlacionar as novas bases epistemológicas, segundo as quais inserimos nosso trabalho.

O dilema principal observado nos estudos semióticos refere-se à dissociação entre o que se considera o seu modelo padrão, exposto acima, e os seus desdobramentos tensivos. Estabelecemos que os desdobramentos recentes da semiótica não se opõem à semiótica padrão, discursiva, mas complementam-se a ela, ao tratarem de modo mais evidente a categorização do nível profundo, somados a análise das práticas semióticas.

As bases epistemológicas nas quais inserimos nosso trabalho pautam-se na correlação entre a semiótica padrão e seus novos desdobramentos tensivos, ao incluírem a noção de práticas semióticas (FONTANILLE, 2008), com a dimensão alicerçada para além do mero aparato textual presente nos textos. Vejamos como Fontanille (2008) considera o nível de eficiência das práticas:

As práticas recebem uma "forma" (constituintes) de sua confrontação com outras práticas e, por isso, de um lado, integram os elementos materiais dos níveis inferiores (signos, textos, objetos) para torna-los elementos distintivos e pertinentes e lhes dar "sentido", e de outro lado, recebem um "sentido" de sua própria participação nos níveis superiores (estratégias e formas de vida). (FONTANILLE, 2008, p. 23).

Tendo apenas pontuado as bases epistemológicas segundo a qual inserimos nosso trabalho, detemo-nos, na sequência, na correlação entre os estudos semióticos e os estudos acerca de religião/religiosidade.

A inclusão dos estudos referentes ao âmbito religioso na semiótica greimasiana coincidem com a publicação da obra Du Sens (GREIMAS, 1970) / (GREIMAS, 1975). Tomaremos como base os desenvolvimentos de Silva (2013), Chabrol (1980), Thériault (2006) e Panier (1986; 1989; 2008), ao elaborarem o histórico desses estudos. Inicialmente, os autores expõem a importância de uma 
seção de três dias realizada no Grand Semináire de Versailles, em setembro de 1968, como o marco inaugural dos estudos em semiótica bíblica. Panier (1989) destaca ainda, que a presença da semiótica no debate do campo de estudos exegéticos tem início na França, a partir do Congresso de 1969 da Associação Bíblica Francesa para o estudo da Bíblia (A.C.F.E.B). Os debates provenientes desse encontro foram publicados sob o título Exégèse et Hermenéutique, Paris, Seuil, Col. Parole de Dieu, 1971. Esses estudos tiveram posterior desenvolvimento em Lyon, por meio da criação, por iniciativa de J. Delorme e J. Calloud, do Centre pour l'Analise Du Discours Religieux (CADIR), com a publicação do periódico Sémiotique et Bible.

A presença da semiótica narrativa no que concerne aos estudos acerca da linguagem da religião, tem início por meio do desenvolvimento dos estudos acerca da interpretação de enunciados bíblicos. O processo de interpretação e análise do enunciado bíblico é entendido como um processo de leitura. A leitura é vista como um processo enunciativo. A leitura para Chabrol (1980, p. 3) refere-se a um perderse o texto e o sentido, de maneira que em seu lugar passamos a constituir um “sujeito desejando saber". Esse sujeito, em sua busca, não se pauta meramente em conformidade às premissas do enunciado elementar proposto pela semiótica em busca de seu objeto de valor, mas do próprio desejo. Temos, assim, "um saber sobre o desejo que instaura essa relação de interlocução em que se faz sua leitura" (CHABROL, 1980, p. 3). Estabelece-se, assim, conforme o autor, uma relação fundadora de um narrador e de um leitor textuais. Essa primeira relação, prevista no plano da enunciação, também pode ser concebida no plano do enunciado, mediante a associação entre destinador e destinatário.

Segundo Chabrol (1980, p. 3), a relação destinador-destinatário, para além da transmissão de um objeto de comunicação ou de saber e de um objeto de desejo, organiza-se segundo um fazer querer, saber e poder pressupostos, os quais deverão corresponder no destinatário, um querer do querer, um saber do saber e um poder do poder, igualmente pressupostos. Conforme Chabrol: 
O contexto que interessa ao analista não é (ao menos numa primeira etapa) o conjunto do contexto sociológico, e sim o contexto mitológico ou, mais globalmente textual, que se apresenta com o observa Greimas (VII [1969 - notas], p. 33), sob forma de conteúdos investidos, independentes da própria narrativa e, posteriormente, sustentados pelo modelo narrativo. (CHABROL, 1980, p. 6).

De modo semelhante ao desenvolvimento do histórico dos estudos linguísticos e sua determinação científica, esboçado na seção anterior, o início do desenvolvimento dos estudos bíblicos na teoria semiótica também foi pautado, inicialmente, por uma problemática filológica e histórica.

Assim sendo, de modo semelhante ao desenvolvimento da linguística de base estrutural (CHABROL, 1980, p. 7), a análise semiótica tem por base o estudo da sincronia. Isso, "não porque ela negligencie as fontes ou estados anteriores desses textos, mas porque os subordina à elaboração dos modelos sincrônicos, que fornecem um modelo hipotético dos estados da língua ou do discurso" (CHABROL, 1980, p. 7). A semiótica ao pautar-se, portanto, no desbastamento dos sentidos dos textos, utiliza-se da leitura não apenas para descrever o seu objeto, mas para se reescrever graças a ele (CHABROL, 1980, p. 9).

A prática de leitura permeada pela análise, inicialmente desenvolvida tendo por base o corpus bíblico, permitiu a rearticulação entre certos elementos da teoria semiótica, notadamente, segundo Panier (2008), entre a dimensão figurativa do discurso e sua relação com a problemática da enunciação.

A experiência de leitura desenvolvida pela semiótica apresenta-se, conforme Panier (1986, p. 267), sob a denominação do termo "comentário", definido pelo autor "provisoriamente como um discurso produzido a partir de um primeiro discurso e que se apresenta como equivalente do ponto de vista do sentido". Podemos considerar, portanto, o comentário como um discurso segundo. Na coletânea organizada por Greimas e Landovski (1986), em que se procura tratar da presença dos discursos em ciências humanas estudados pela semiótica, Panier (1986) tenta demonstrar o lugar em que se encontram os discursos de comentário. 
O comentário é um discurso segundo em que se indica e se realiza a passagem de uma narrativa (discurso figurativo) ao discurso não figurativo que toma essa narrativa como objeto, e com que se manifestam os procedimentos que se encontram igualmente em funcionamento nos discursos com pretensão científica. (PANIER, 1986, p. 268).

Segundo Panier (1986, p. 268) a Semiótica narrativa e discursiva está em plenas condições de analisar tanto a narrativa quanto seu comentário. Ao longo do capítulo, Panier se debruça em dois problemas fundamentais à análise dos comentários, quer seja as duas categorias de desempenho efetuadas por esses discursos: a) o fazer comunicativo ou persuasivo: "o comentário transmite um saber que se pretende a verdade"; b) fazer interpretativo "o comentário interpreta a narrativa que toma por objeto" (PANIER, 1986, p. 268). Assim sendo, Panier destaca que, se de um lado "o comentário comunica um saber", de outro "o comentário interpreta o texto de base”. (PANIER, 1986, p. 268). Panier procura, portanto, estabelecer uma tipologia dos discursos de comentário, entendido como “objeto comunicável que se chama habitualmente a interpretação do texto (PANIER, 1986, p. 268). Assim sendo, segundo o tipo de comentário efetivado teríamos diferentes categorias de objetos narrativos: a) objeto modal (comentário prescritivo e comentário parenético); b) objeto valor (comentário informativo); c) objeto mensagem (comentário laudativo) (PANIER, 1986, p. 272). Os papéis e figuras da narrativa de referência encontram-se, segundo o autor, desenvolvidos na narrativa de comentário em novos programas e em novas isotopias, de maneira que "a narrativa de comentário completa as sequencias lacunares da narrativa de referência" (PANIER, 1986, p. 276). Assim sendo, temos na interpretação efetivada pela semiótica a recategorização das figuras da narrativa evangélica/religiosa de base, convertidas em uma relação sêmica específica, responsável pela reorganização das isotopias da narrativa fundadora. Ainda segundo Panier (1986, p. 278), "as realizações semânticas da narrativa de referência são restituídas no comentário à sua virtualidade semiótica”. 


\section{Conclusão}

Cabe destacar que todo o posicionamento apresentado recoloca no centro das discussões a divisão entre hermenêutica, exegese e análise semiótica. Ao que Chabrol (1980, p. 5) destaca que, "havendo uma dicotomia, esta seria entre uma análise não semiótica dos textos". Afirmação que, ao invés de nos afastar dos posicionamentos tecidos por Nogueira (2016), ao correlacionar e situar a área de estudos denominada Linguagens da Religião, mais nos aproxima dela. Ao definir a problemática na qual a área de estudos acerca das Linguagens da religião se situa, Nogueira (2016) procura diferenciar-se das áreas de estudo de comunicação religiosa e dos estudos de mídia e religião. Do mesmo modo que a área que trata das Linguagens da Religião difere-se de propostas centradas nos aspectos de comunicação religiosa e nos aspectos de relações midiáticas, tomando por base os aspectos mais elementares da religião e linguagem, assim também o faz a semiótica greimasiana da qual trabalhamos. O que os estudos de Linguagem e religião procuram tratar, segundo Nogueira (2016), é a correlação entre o dualismo entre linguagem (forma de expressão) e religião (conteúdo), de modo semelhante, a nosso ver, com o que a semiótica de base saussuriana e hjelmsleviana, notadamente em seus desenvolvimentos atuais, estabelece. O autor não deixa de mencionar ainda que, alicerçado a toda uma experiência religiosa oriunda das práxis, que "muitas de nossas experiências religiosas são induzidas pela linguagem por meio de hinos, orações, mantras, e na leitura de textos, etc" (NOGUEIRA, 2016, p. 244). Todo o alicerce epistemológico apresentado pelo autor insere-se nos estudos da semiótica da cultura de Iuri Lotman, entretanto, conforme correlacionamos na introdução deste artigo, julgamos de extrema importância apresentar os estudos acerca dos desenvolvimentos efetuados pela semiótica greimasiana que, em seus últimos desenvolvimentos, sobretudo mediante a noção de prática semiótica, acrescida dos novos desdobramentos do modelo tensivo também não se reduz meramente ao estudo do código linguístico, incluindo as práticas que lhe são organizadoras, o que é premente para uma proposta que esteja alicerçada no tratamento da religião, especialmente, no que diz respeito aos novos objetos religiosos que se tem contemporaneamente. 
Tomamos a religião como prática social, tomada no espaço tensivo das práticas (Fontanille, 2008), ademais, se considerarmos a mudança ocorrida nos objetos e práticas de fé, no que condiz com a significação da linguagem religiosa vigente nos meios de comunicação de massa e na série quase ilimitada de mídias digitais presentes em uma série de dispositivos, entre televisores, smartphones, tablets e computadores. Entretanto, esse é objeto de estudo posterior. Esperamos, assim, ter contribuído com a apresentação de uma epistemologia diferenciada no que concerne ao tratamento das linguagens da religião.

\section{REFERÊNCIAS}

ALVES, Rubem. O que é religião. 6. ed. São Paulo: Loyola, 2005.

BARROS, D. L. P. Teoria semiótica do texto. São Paulo: Ática, 2005.

BENVENISTE, E. Problemas de linguística geral I. 5. ed. Campinas, SP: Pontes Editores, 2005.

BÍBLIA SAGRADA AVE MARIA: edição de estudos. 3. ed. São Paulo: Editora Ave Maria, 2017.

BORBA, F. S. Introdução aos estudos linguísticos. 6. ed. São Paulo: Editora Nacional, 1979 .

CHABROL, C. Problemas da semiologia narrativa dos textos bíblicos. In: CHABROL, C.; MARIN, L. Semiótica narrativa dos textos bíblicos. Rio de Janeiro: Forense Universitária, 1980, p. 2-12.

FIORIN, J. L. Introdução à linguística I. São Paulo: Contexto, 2003.

FIORIN, J. L. Elementos de análise do discurso. 13. ed. São Paulo: Contexto, 2005.

FIORIN, J. L. Linguística? Que é isso? São Paulo: Contexto, 2013.

FONTANILLE, J. Práticas semióticas: imanência e pertinência, eficiência e otimização. In: DINIZ, Maria Lúcia Visotto Paiva; PORTELLA, J.C (Org.). Semiótica e mídia: textos, práticas e estratégias. Bauru: UNESP; FAAC, 2008.

GREIMAS, A. J. Du sens. Paris : Éditions du Seuil, 1970

GREIMAS, A. J. Sobre o sentido. Rio de Janeiro: Vozes, 1975. 
GREIMAS, A. J; COURTÉS, J. Dicionário de semiótica. São Paulo: Contexto, 2008.

GREIMAS, A. J; LANDOWSKI, E. Análise do discurso em ciências sociais. São Paulo: Global, 1986.

LYONS, J. Linguagem e linguística: uma introdução. Rio de Janeiro: LTC, 2011.

MUSSALIM, F. Bentes. Introdução à linguística: fundamentos epistemológicos. São Paulo: Cortez, 2006. v. 3.

NOGUEIRA, P. A. S. Religião e linguagem: proposta de articulação de um campo complexo. Horizonte, Belo Horizonte, v. 14, n. 42, 2016. Disponível em:<http://periodicos.pucminas.br/index.php/horizonte/article/view/P.2175-

5841.2016v14n42p240>. Acesso em: 26 jul. 2018.

NORMAND, C. Convite à linguística. São Paulo: Contexto, 2009.

PANIER, Louis. O discurso de interpretação no comentário bíblico. In: GREIMAS; LANDOWSKI. Análise do discurso em ciências sociais. São Paulo: Global, 1986.

PANIER, L. Une lecture semiotique des textes: questions de theologie biblique. In: Semiotique et Bible, Lyon, Centre pour l'analyse du discours religieux, n. 56, déc. 1989, p. 19-36.

PANIER, L. Sémiotique et etudes bibliques. Évolutions méthodologiques et perpectives épistemologiques. EC - Rivista dell'Associazone Italiana Studi Semiotici, 28 febbr. 2008. Disponível em:<www.ec-aiss.it>. Acesso em: 30 jun. 2018.

SAUSSURE, F. Curso de linguística geral. São Paulo: Cultrix, 1975.

SILVA, S. M. R. O discurso fundador na esfera religiosa. In: JESUS, Sérgio Nunes de; SILVA, Sueli Maria Ramos da Silva (Org.). O discurso e outras materialidades. São Paulo: Pedro e João Editores, 2013. p. 57-81.

THÉRIAULT, J-Y. Quand la bible s'ouvre à la lecture sémiotique. Proteé: revue internationale de théories et de pratiques sémiotiques, v. 34, n. 1, p. 67-75, 2006. 